\title{
LA PRESENCIA DE LOS CHIRICANOS EN EL PACÍFICO SUR DE COSTA RICA: APORTES DESDE LA GEOGRAFÍA HISTÓRICA
}

\author{
THE PRESENCE OF CHIRICANS IN THE SOUTH \\ PACIFIC OF COSTA RICA: CONTRIBUTIONS FROM \\ HISTORICAL GEOGRAPHY
}

\author{
Carlos Morera Beita ${ }^{1}$ \\ Universidad Nacional de Costa Rica, Costa Rica \\ Silvia Meléndez Dobles ${ }^{2}$ \\ Universidad de Costa Rica, Costa Rica
}

"La frontera es punto de encuentro, no de confrontación; físicamente es la calle común..." Cuevas (1999:397)

http://dx.doi.org/10.15359/rgac.3-59.3

\section{RESUMEN}

Este artículo analiza la presencia de los chiricanos en el Sur de Costa Rica, apoyado en referencia secundaria y centrada en la reconstrucción de sus rutas de ocupación. En los cimientos de la región fronteriza entre Costa Rica y Panamá se ubica un pueblo transfronterizo, que durante la época colonial e independiente fue fraccionado, pero que, aún en este siglo se resiste a ser asimilado por la cultura occidental como es el caso de los ngäbe buglé. Los chiricanos, como se le denomina a los

1 Doctor, Profesor de la Escuela de Ciencias Geográficas, Universidad Nacional de Costa Rica, Costa Rica. Correo electrónico: cmorera@una.cr

2 Master, Profesora de la Escuela de Geografía, Universidad de Costa Rica, Costa Rica. Correo electrónico: silmelendez@gmail.com

Fecha de recepción: 06 de setiembre de 2016

Fecha de aceptación: 24 de febrero de 2017 
Carlos Morera Beita, Silvia Meléndez Dobles. The presence of chiricans in the South Pacific of

Costa Rica: contributions from historical geography

pobladores de la provincia vecina de Chiriquí, llegaron a obtener refugio por las guerras acaecidas en el territorio que actualmente ocupa Panamá, en procura de áreas de pastoreo o tierras agrícolas, y finalmente pasan a ser mano de obra en las plantaciones bananeras; son el mismo tejido del campesinado mestizo que dominó en las regiones costeras del país tanto en el Caribe como en el Pacífico, lo cual facilitó su fusión con otros grupos. Este artículo evidencia que el concepto de frontera responde a razones más políticas que culturales, debido a que el territorio es un continuo, especialmente en regiones fronterizas.

Palabras clave: Ocupación de Costa Rica, Migración en Costa Rica, Geografía Histórica, Pacífico Sur, Chiricanos.

\begin{abstract}
This article analyzes the presence of chiricanos in Southern Costa Rica. All this is based on secondary references and focused on rebuilding their occupation routes and some geographical factors. In the foundations of these border regions of Costa Rica and Panamá there is a cross-border people that, during the colonial and independent times, was fragmented, but even in this century, they still resist. This is the case of the Ngäbe Bugle. Due to the wars that took place in the territory currently occupied by Panama, Chiricanos -as people from the Chiriquí province are called, came to look for refuge, grasslands, agricultural lands to finally work at banana plantations. They are the same social network of the mestizo peasantry that dominated the coastal regions of the country -both in the Caribbean and in the Pacific, which facilitated their fusion with other local groups. This article shows that the concept of border responds to political rather than to cultural reasons, because the territory is a continuum, especially in border areas.
\end{abstract}

Keywords: Colonization of Costa Rica, Migration in Costa Rica Historical Geography, South Pacific, Chiricanos.

\title{
Introducción
}

Dentro de la geografía histórica abundan las investigaciones que abordan las migraciones como la realizada por Sassone (2009) sobre los flujos migratorios de bolivianos en la Argentina. Igual, destaca Duany (2010) que analiza las diásporas en las Antillas hispánicas (Cuba, República Dominicana y Puerto Rico), trazando un perfil demográfico y describiendo su trascendencia económica para los países emisores.

En el caso de Costa Rica, en los últimos años se ha presentado un debate que revisa los aportes de otros grupos étnicos como los afrodescendientes y los indígenas a la identidad costarricense, intentado superar el estereotipo de un país homogéneo de raíz europea (Molina, 2002). El discurso oficial ha defendido que los costarricenses somos los "blancos" del Istmo, y que nuestra cultura es únicamente la del "Valle Central" de Costa Rica como lo plantea Cortes (2010). De tal forma, que la mayoría de libros de historia y geografía del país como Monge (1943), Flores, (1983) y 
Vargas (2012), no abordan acertadamente la contribución de otros grupos sociales a la identidad nacional y mucho menos la dimensión multicultural de Costa Rica.

Durante el periodo entre 1870 y 1930, el auge económico del país atrajo jamaiquinos, italianos y chinos, entre otros, provocando que más de un veinte por ciento del crecimiento poblacional de Costa Rica entre 1895 y 1914 se debiera a la inmigración de extranjeros, siendo la nicaragüense, panameña y estadounidense las más constantes hasta los años 70 (Brenes, 1999). Con la preocupación de superar la visión oficial de un país "blanco", han emergido algunas investigaciones sobre la migración en los últimos siglos, como la que analiza el proceso socio-histórico de los jamaiquinos del Caribe costarricense en el periodo 1872-1950, para identificar cuáles fueron los elementos aglutinadores de las primeras formas de identidades étnicas elaboradas por esta población (Fernández, 1970).

Dentro de la inmigración a Costa Rica destacan los panameños, especialmente los "chiricanos", como se denomina a los pobladores de la vecina provincia de Chiriquí, que contribuyeron a la colonización del Pacífico Sur del país. Considerando el área antes mencionada como un espacio, que desde la perspectiva geográfica puede considerarse como un territorio, un lugar o una región, debido a que no presenta una delimitación precisa en la dimensión espacio-temporal hasta las últimas décadas. Por lo tanto, desde tiempos prehispánicos los territorios fronterizos de lo que actualmente se designan como las repúblicas de Costa Rica y Panamá, estuvieron articuladas dentro de la región cultural conocida como el Gran Chiriquí. Posteriormente, en tiempos coloniales e independientes, considerando que el paisaje como espacio geográfico es la huella de la cultura que lo habita no sólo en su dimensión material, sino también espiritual y simbólica, como plantea (Nogué, 2005), la presencia de chiricanos marcó una impronta en la región Pacífico Sur de Costa Rica, debido a la evidente relación entre transformación y colonización en las sociedades humanas (Head, 2000), aunque esta no se ha precisado en el área de interés.

La única investigación identificada sobre la presencia de los chiricanos en el Sur de Costa Rica, de acuerdo a la revisión de literatura, es la realizada por Amador (2008) sobre el origen chiricano de la comunidad de Potrero Grande, Buenos Aires, desde un enfoque antropológico y utilizando como fuente las entrevistas en profundidad. Así, basado en una de las 
preocupaciones de la geografía histórica como es sus rutas de colonización, así como su distribución espacial (Sauer, 2004), este artículo aborda la dinámica espacial de la presencia de los chiricanos en el Pacífico Sur de Costa Rica, basado en las rutas de colonización.

\section{Metodología}

Considerando que la geografía histórica utiliza fuentes como mapas antiguos, libros de viajeros, novelas, datos estadísticos, entre otros, para indagar sobre los procesos sociales, culturales, económicos y demográficos; y establecer la génesis y evolución de un espacio, esta investigación se fundamenta en la revisión de documentos como libros, novelas, artículos e informes, los cuales fueron exiguos debido a que es tema escasamente investigado y que carece de referencias cuantitativas, debido posiblemente, a que los chiricanos ingresaron a lo que en actualidad son territorios de Costa Rica de forma desagregada y prontamente se fusionaron con otros pobladores de esta región. Además, el análisis se sustenta en algunas entrevistas de fuentes secundarias y fotografías que testimonian la presencia de chiricanos en el Pacífico Sur de Costa Rica. Para organizar la discusión, el artículo se estructura en dos apartados principales; el primero, aborda los tiempos prehispánicos y coloniales, mientras en la segunda parte, se analizan los siglos XIX y primera mitad del siglo XX del área de estudio.

\section{Unidad Prehispánica y el Camino de las Mulas}

Desde tiempos prehispánicos, lo que en la actualidad se denomina como el Pacífico Sur de Costa Rica, en la regionalización oficial del país como Brunca o, en el lenguaje popular Zona Sur, perteneció a una unidad cultural con el oeste de Panamá, que se conoce como el Gran Chiriquí. De acuerdo a Tous (1996), esta sub-área de la Baja América Central estuvo integrada por: Diquís, formada por las planicies y la costa sur de Costa Rica; Chiriquí, que comprende la costa noroeste de Panamá; la provincia de Bocas del Toro, en la costa Caribe de Panamá, y Talamanca, donde se localizan los pueblos tierra adentro entre Costa Rica y Panamá.

El Gran Chiriquí no presentaba límites como los estados actuales, y posiblemente los grupos sociales que lo habitaban se movían constantemente en función de la sobrevivencia, como lo testifica en la actualidad el caso de la etnia ngäbe buglé (denominados popularmente guaymies), 
debido a que la construcción de las fronteras nacionales transformó a estas personas en extranjeras de su propio territorio (Morales, Lobo, y Jiménez, 2014). Barrantes (1998) establece una fuerte correlación genética entre los ngäbe buglé, los borucas, los bribris, los cabécares, los teribes (o nasos) y los malekus (o guatusos) y, en menor medida entre y los kuna y los huetares, especialmente entre estos dos primeros, lo cual verifica la conexión cultural de estos grupos étnicos, aunque en la actualidad se reconozcan como poblaciones diferenciadas.

Desde tiempos prehispánicos la región del Gran Chiriquí conformó una unidad cultural que se ubicaba en una región fronteriza entre el Virreinato de Nueva España (Centroamérica, México, las Antillas y parte de los Estados Unidos de América) y el Virreinato de Nueva Granada (Ecuador, Colombia, Venezuela y Panamá). En la época colonial, las unidades político-administrativas estaban divididas en extensos territorios poco explorados y conocidos, y que con la Independencia de España se enfrentaron a la tarea de trazar límites exactos sobre esas áreas fronterizas. La figura 1 muestra la representación del límite sureste de Costa Rica con Colombia, basado en una interpretación realizada por la Librería de Hernando [18701900], que evidencia que la región, que culturalmente se denomina Gran Chiriquí, quedaba dividida por una frontera. 
Carlos Morera Beita, Silvia Meléndez Dobles. The presence of chiricans in the South Pacific of Costa Rica: contributions from historical geography

Figura 1. Parte de límite entre Costa Rica y Panamá de 1890

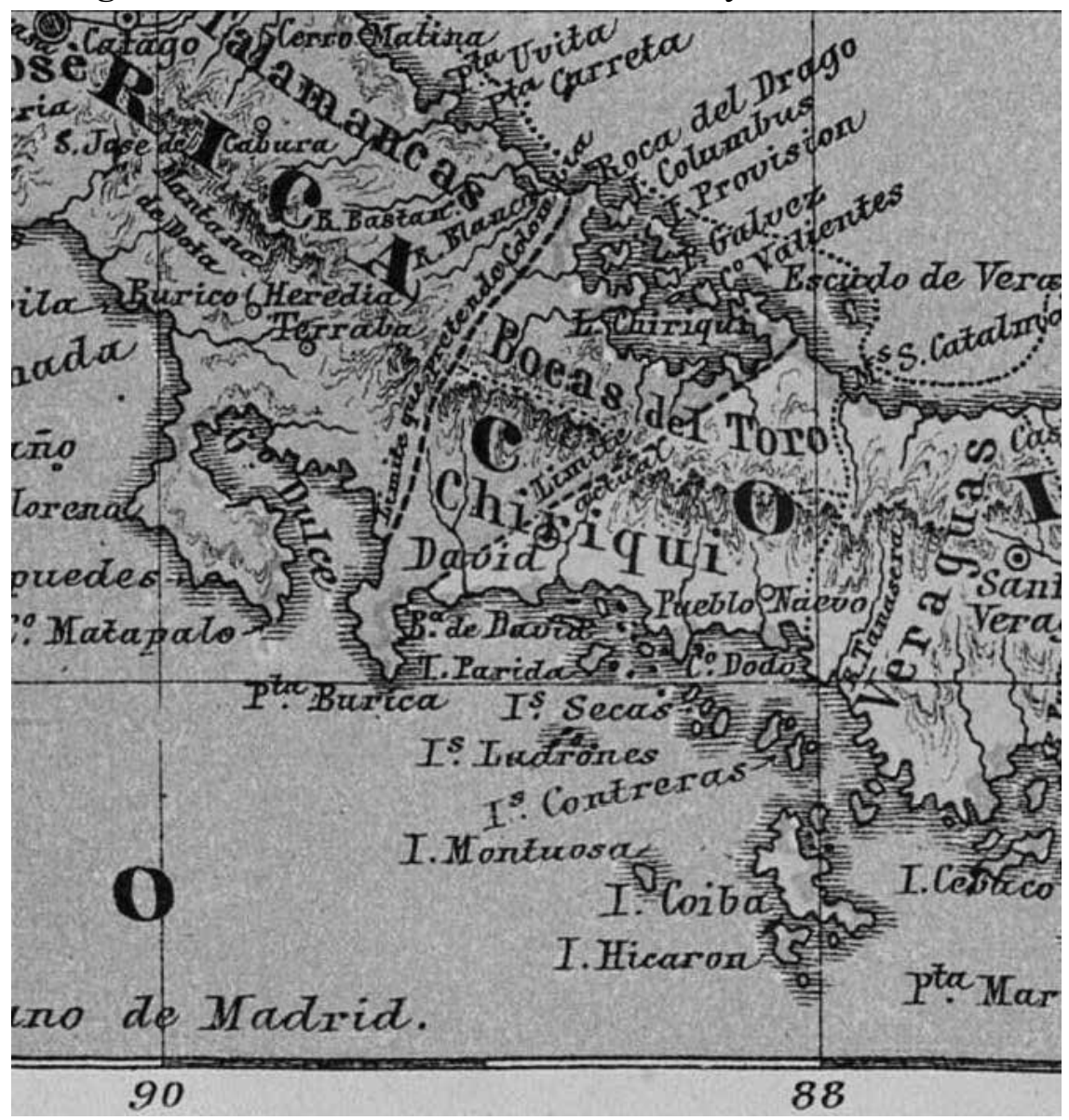

Fuente: Reinoso, J. H. Litografía J.M. Mateu. Librería de Hernando, Madrid. [1870-1900]

En 1810, una de las primeras acciones americanas para definir los territorios de los nuevos estados nacionales fue recurrir al término en latín del "Uti possidetis", el cual consiste en reconocer que "poseeremos como poseíamos". Esta fue la fórmula de los derechos territoriales, sin embargo, desgraciadamente, esta proposición se estructuró sobre andamios frágiles, debido a que no existía una delimitación precisa entre las unidades administrativas coloniales. De esta forma, las líneas fronterizas

3 Tomado de Biblioteca Digital Hispánica, http://bdh-rd.bne.es/viewer.vm?id=0000020484. [Consultado el 31 agosto 2016]. 
fueron trazadas de conformidad con las disposiciones reales españolas sobre divisiones vigentes al tiempo de la independencia. No obstante, el principio del "Uti possidetis" resultó ser un mecanismo para la evasión de problemas, que posteriormente surgieron cuando se requirió realizar negociaciones para los trazados fronterizos mediante tratados. De esta forma, el principio del "Uti possidetis" se dividió en dos: el "Uti possidetis de facto", concerniente a ocupaciones territoriales de hecho, y el "uti possidetis juris", el cual se refería al fundamento jurídico que definía las unidades administrativas bajo el régimen español. Ambos principios eran excluyentes, así que se respetaba las ocupaciones territoriales de hecho, o se aplicaba los documentos específicos emanados a partir de la Corona española (Sibaja, 1968).

La definición limítrofe del litoral pacífico de Costa Rica fue difícil, debido a que, si se aplicaba el criterio de "uti possidetis juris" la región de David y Alanje quedarían en territorio costarricense, por lo que se genera un reconocimiento a la ocupación territorial de hecho por el proceso de colonización chiricano, predominando un criterio de "uti possidetis de facto". Por lo cual, los argumentos en este caso no tienen un fundamento jurídico emanado de las cédulas reales (Ibid.).

Desde principios de la época colonial, concretamente en 1601, con el objetivo de comunicación con el reino de Tierra Firme se abrió el Camino de Mulas (Figura 2), conocido así, porque las condiciones agrestes de esta vereda posibilitaban que únicamente fueran transitadas por estas bestias en época seca hacia las Ferias de Portobello. Esto generó una inmensa demanda de mulas que fue aprovechada especialmente por Costa Rica y Nicaragua entre los años 1660 y 1753 (Amador, 1978). Esta ruta fue un medio de comunicación que reafirmó la conexión entre Panamá y Costa Rica. 
Figura 2. Ruta del Camino de Mulas.

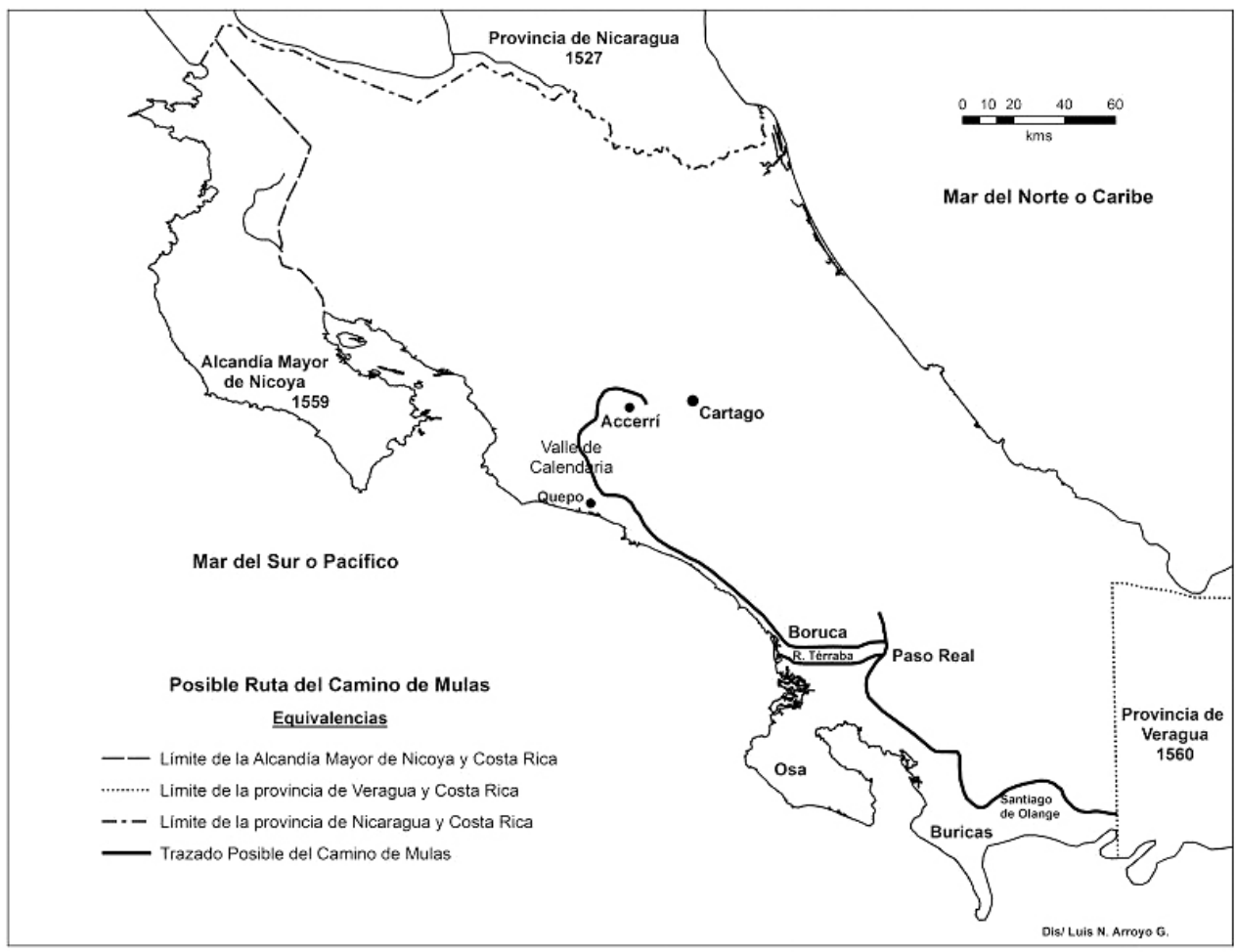

Fuente: Amador, 1978

Un factor relevante de los procesos migratorios chiricanos en el área de estudio es que en 1602 se funda David, ubicada en las tierras bajas entre el Volcán Barú y el área costera, la cual se localiza en las márgenes del río del mismo nombre, el cual es afluente del río Chiriquí en un punto de enlace entre Remedios y Alanje, que a su vez conectan con la ciudad de Panamá. Esta localidad fue fundada por orden del Capitán Juan López de Sequeira, portugués naturalizado español, Gobernador del Ducado de Veragua que se especula que era de origen judío, lo cual explica que le bautizó con este nombre (Osorio y otros, 1974).

David tiene una función crucial en el desarrollo histórico y social de la futura provincia de Chiriquí y de Panamá. Durante la expansión de la ecúmene del actual territorio panameño para el siglo XVIII, se genera un proceso de apropiación del antiguo Ducado de Veragua y una incorporación 
dentro de lo que en la actualidad es Panamá (Sanders, 1964). Esto es fundamental para la definición territorial entre Costa Rica y Panamá, pues el proceso de colonización panameño llegaba allende del límite de dicho Ducado, límite "oficial” con la Provincia de Costa Rica. En este caso, se presentó un proceso de ocupación efectiva mediante colonización proveniente desde Panamá, lo que significó una ocupación en toda la región por población panameña.

A diferencia de Panamá, el poblamiento costarricense partía desde el "Valle Central" y fue exiguo en territorios periféricos como es el caso de la región del Pacífico Sur. Fue hasta el siglo XX que las autoridades asumen una función activa en políticas de poblamiento del sector fronterizo, para asegurar el control nacional en esas tierras, hasta entonces ocupadas por panameños (Meléndez, 2010).

La conexión histórica con Panamá, por su cercanía geográfica y la lejanía de Guatemala, generó un vínculo entre estas regiones que se identifica cuando en 1622 el Cabildo de Cartago dirigió al Rey de España un informe, solicitando la segregación de la provincia de Costa Rica al Cabildo de Guatemala y la agregación a Panamá, lo cual no se logró por la oposición de Guatemala (Saborío, 1941). En la primera mitad del siglo XVII, se establece la reducción de Boruca, conformada por Fernández (1976), refiriéndose a una carta fechada en el año de confinar a este lugar indígenas de las provincias de León, Esparza y Chiriquí que concurran "santo sacrificio de la misa" para procurar su defensa de los indígenas caribes y zambos mosquitos. La anterior nota muestra como Chiriquí ya era una región conocida para este periodo. Entre los años 1650 y 1655, el gobernador Juan Fernández de Salinas y la Cerda, con el objetivo de acabar los ataques indígenas repobló Boruca con indígenas obtenidos de las montañas (Solórzano, 2013), lo cual se transforma en la primera comunidad de ocupación permanente en el Pacífico Sur de Costa Rica en tiempos de la colonia y de independencia.

Desde David se generan movimientos migratorios, que incluso llegaron hasta el puerto de Golfito por el lado del Pacífico y a las llanuras del río de la Estrella por el lado del Caribe. Concretamente, ese es el origen de la Usurpación granadina del territorio de Bocas del Toro y sus islas en 1836 por parte del gobierno del General Santander, previa colonización por parte de pobladores de origen extranjero (Fernández, 2005). 


\section{La ocupación de los Chiricanos del Pacífico Sur de Costa Rica en el siglo XIX y primera mitad del siglo $\mathrm{XX}$}

La colonización del Pacífico Sur de Costa Rica fue tardía. En 1869, se inicia por Pedro Calderón, la ruta conocida como picada Calderón que fue el primer proceso de integrar el área de estudio al desarrollo nacional, y se implementa el frente de colonización que se concentró en el Valle del General, llegando hasta Buenos Aires, especialmente con campesinos de Santa María de Dota (Barrantes, 2015). Mientras que, en Panamá, los españoles concentraron su presencia en el corredor transístmico y en la franja que se extiende desde Chepo, al este de la ciudad de Panamá, hasta Natá en el oeste, con prolongaciones posteriores hacia Veraguas y después hacia la región de Alanje en Chiriquí durante el siglo XVI con dos elementos fundamentales: el ganado vacuno y caballar, y el régimen económico y social estructurado en torno a la importación masiva de esclavos africanos (Herrera, 2006).

Destaca dentro de la revisión bibliográfica la novela escrita en 1926 por la profesora, Caridad De Salazar de Robles, de origen canaria, titulada Robinson Tico. La trama es un viaje desde Cartago a Chiriquí para vender ganado de dos personas atravesando el agreste Pacífico Sur a mediados de 1800, que evidencia la conexión comercial existente entre estas dos áreas (De Salazar, 1993).

Se pueden identificar, espacialmente, dos rutas de migración de Chiricanos al área de estudio: una fluvial-costera y otra terrestre (Mapa 1 y Cuadro 1). Estas difieren a las identificadas por Amador (2008), quien establece tres, separando la costera y la fluvial mientras que en este artículo se unifican, debido a que no se encontró evidencia de una ruta exclusivamente costera y aún en la actualidad la conexión de Burica se realiza por el poblado de Limones, localizado en territorio panameño. Burica fue un espacio que permaneció aislado hasta 1950-1960 en que una ocupación de chiricanos coloniza desde este mismo poblado aunque de acuerdo a García (1988) en 1923, del sector de Río Coto a Punta Burica, la actividad económica se centraba en explotación cocotera que abastecían a las fabricas nacionales de aceites de San José, y que presenta la interrogante de cómo estas tierras fueron incorporadas al desarrollo nacional mucho antes que otras de mayor cercanía y qué causo su posterior abandono. 
Por otro lado, estas dos rutas de ocupación, deberían estar entrelazadas entre El Pozo (Actual Puerto Cortés) y Boca del Río Naranjo, porque se alinean varios pueblos alrededor del antiguo Camino de las Mulas, que evidencian el origen de los migrantes como San Andrés y Barú, nombres que se puede relacionar con pueblos chiricanos de donde procedían sus fundadores. 
Carlos Morera Beita, Silvia Meléndez Dobles. The presence of chiricans in the South Pacific of Costa Rica: contributions from historical geography

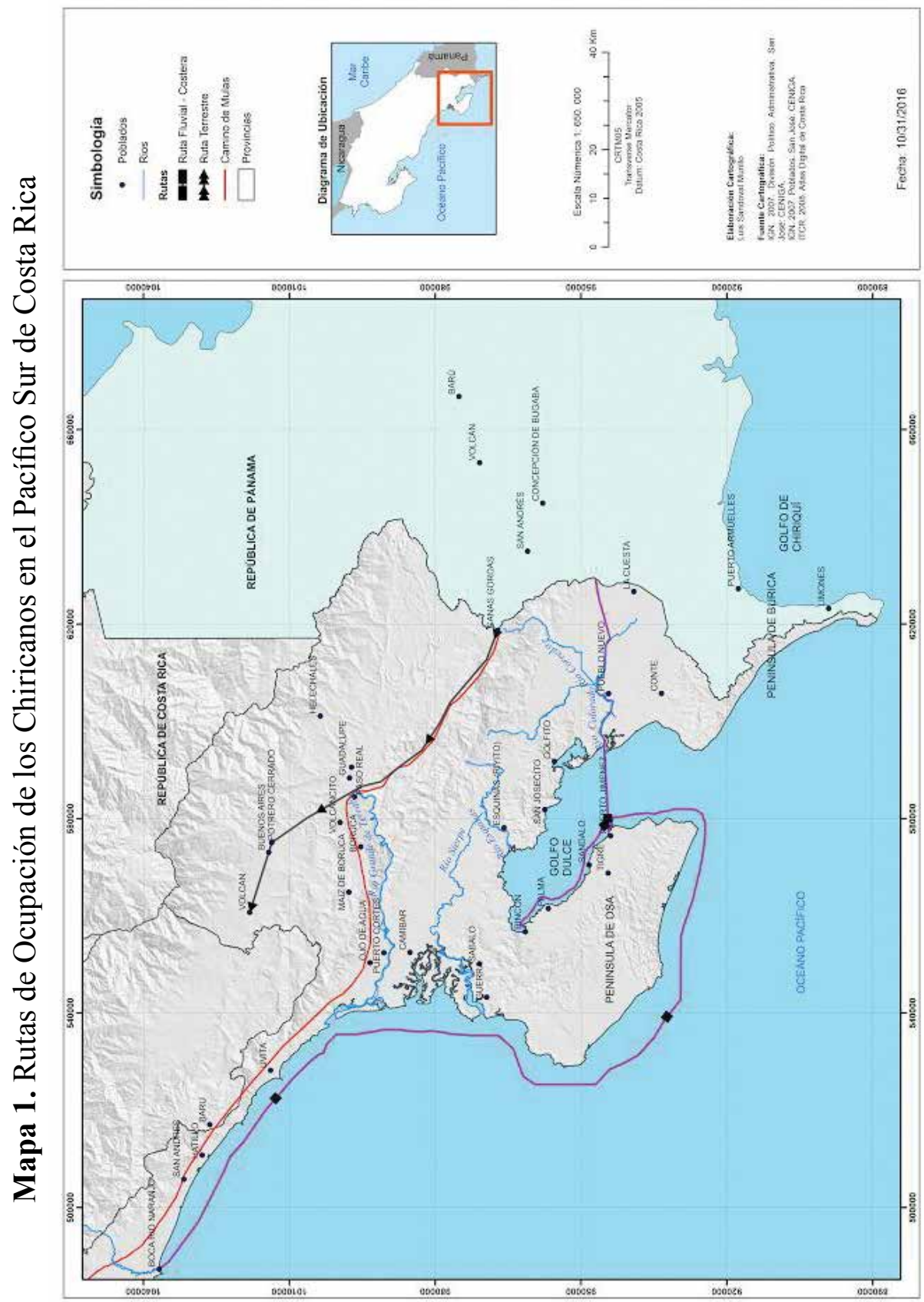


Tabla 1. Ruta de ocupación, poblados y algunos apellidos de origen o fuerte presencia chiricana en el Pacífico Sur de Costa Rica.

\begin{tabular}{|c|c|c|}
\hline Ruta de Ocupación & Asentamientos y Poblados & Algunos apellidos Asociados \\
\hline Fluvial y marítima & $\begin{array}{l}\text { Pueblo Nuevo, El Tigre, Rincón, } \\
\text { La Palma, San Josecito, Ojo de } \\
\text { Agua, Estero, Guerra, Sándalo, La } \\
\text { Cuesta Buríca, Boca de Zacate, San } \\
\text { Andrés, Agujas, Puerto Jiménez, } \\
\text { Uvita, Conte, Boca del Río } \\
\text { Naranjo, Dominical, Estero Azul. }\end{array}$ & $\begin{array}{l}\text { Franchesi, Rodríguez, Zavala, } \\
\text { Quintero, Lezcano, Barraza, } \\
\text { Gómez, Cedeño, Araúz, Palacios, } \\
\text { Serrú, Reyes, Bellanera. } \\
\text { Orellana }\end{array}$ \\
\hline Terrestre & $\begin{array}{l}\text { Volcán, Potrero Grande, Helechales, } \\
\text { Guadalupe de Potrero Cerrado, } \\
\text { Cañas Gordas. }\end{array}$ & $\begin{array}{l}\text { Guerra, Atencio, Cedeño, } \\
\text { Grajales, Villarreal, Morales, Pitti, } \\
\text { Beita, Pinzón, Valdéz, Saldaña, } \\
\text { Altamirano, Serracín }\end{array}$ \\
\hline
\end{tabular}

Fuente: Elaboración propia a partir de la bibliografía consultada.

\section{a. Ruta de ocupación fluvial y costera}

Aproximadamente de 1800 a 1920 se presentó una ocupación aislada de las diversas bahías y ensenadas que se presentan en la irregular costa del Pacífico Sur, desde Burica hasta cerca de Puntarenas (posiblemente hasta la Boca del Río Naranjo), que mantenían vínculos filiales o se consideraban parientes entre sí, aunque no lo fueran realmente y que migraron forzados por la estructura latifundista de la ganadería (Barrantes, 2014). Existe muy escasa información sobre este periodo, lo que se puede encontrar son algunas evidencias de poblados que fueron establecidos durante esta época. En este recorrido se pueden localizar dos rutas, la principal fue un pequeño tramo terrestre desde el poblado de Bugaba de la Concepción hacía el noroeste donde se establecieron: La Cuesta y Conte. Posteriormente, utilizando el Río Coto Colorado, los campesinos chiricanos navegaron para establecerse en Pueblo Nuevo, y posteriormente cruzar el Golfo Dulce, fundando los asentamientos de Santo Domingo (actual Puerto Jiménez, que fue varias veces reubicado por terremotos y un maremoto), así como El Tigre, Rincón, La Palma, San Josecito. Destaca que la búsqueda de terrenos de vocación agrícola y la conectividad con Panamá provocó que estos pobladores se localizaran en el sector Sur de la Península de Osa, con suelos con mayor vocación para la agricultura y ganadería, donde las condiciones climáticas son menos lluviosas y similares a las de Chiriquí y no son tan adversas comparado con el noroeste de esta área. 
De acuerdo a Cerdas, (1993) fue Juan Mercedes Fernández, un chiricano naturalizado costarricense, quien organizó al grupo de panameños que ocuparon la península de Osa. De acuerdo a los censos en 1883, esa área estaba poblada por 392 personas, las cuales eran principalmente de origen chiricano (Dirección General de Estadísticas y Censos, 1883). En 1892 era de 523 (Dirección General de Estadísticas y Censos, 1892) con un crecimiento de 13,3\% anual y 1195 en 1927 con 6,5\% anual respectivamente (Dirección General de Estadísticas y Censos, 1927). Además, de forma aislada se establecieron las comunidades de Boca Zacate (Comunidad efímera) y Estero Azul en el delta Terraba-Sierpe, así como Ojo de Agua, Barú, Boca del Río Naranjo (Comunidad efímera) y Savegre.

Figura 3. Población de la Península de Osa.

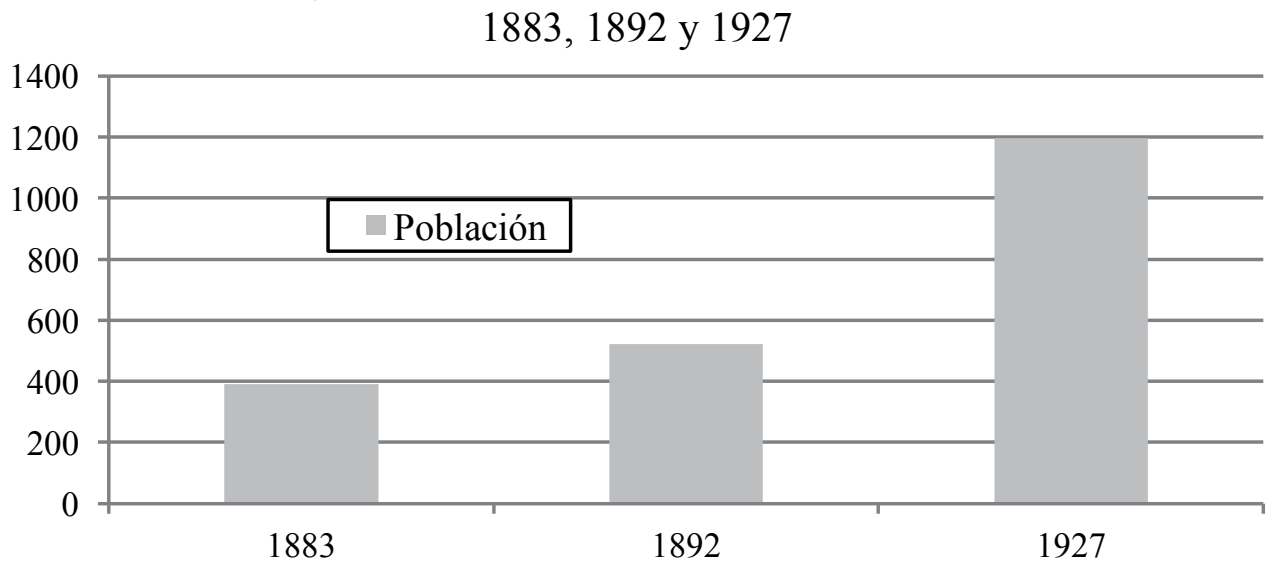

Fuente: Dirección General de Estadísticas y Censos, 1883, 1892 y 1927.

La forma de ocupación generó un modelo de viviendas dispersas conformadas por ranchos de techos de pajas y paredes de madera rolliza o tablones aserrados manualmente, y sin pueblos que nuclearan servicios como se puede contemplar en la figura 4, por lo cual es difícil encontrar vestigios de estos poblados. Este proceso de ocupación desagregado, centrado en un modelo de subsistencia, facilitó la mezcla con grupos sociales como indígenas y migrantes de otras regiones de Costa Rica. 
Figura 4. El Pozo (Puerto Cortés) en 1923

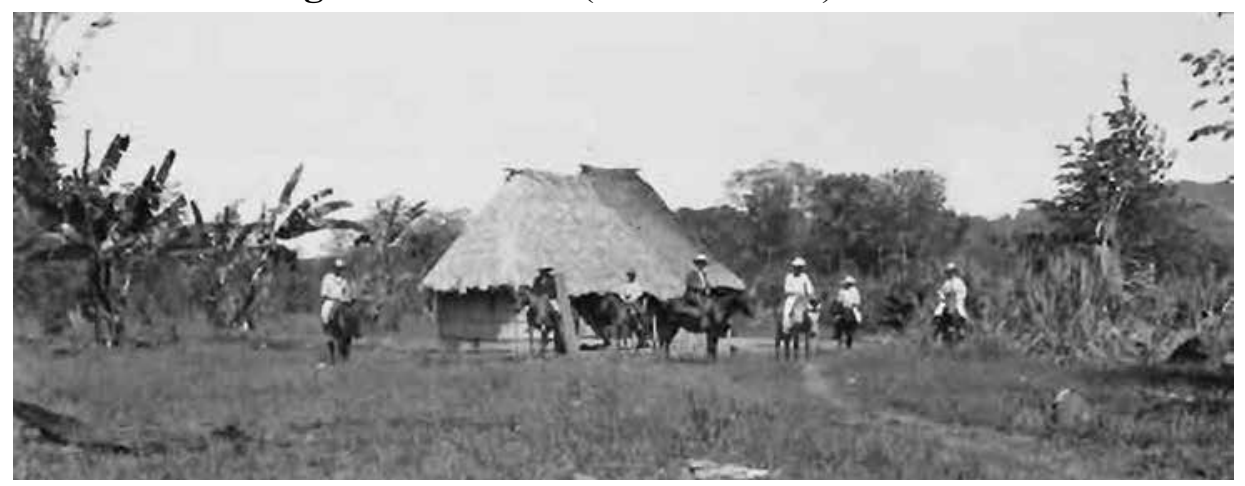

Fuente: Foto Armando Cespedez,1923. Biblioteca Nacional.

En una entrevista a Marciala Gómez Zavala, quien nació en junio de 1932 en Boca Zacate, en el delta Terraba-Sierpe, menciona: "Mi mamá era panameña, de David, Chiriquí. Ahi ella tenía su papá y toda su familia, pero se vino muy jovencita, de unos quince años, y aquí se naturalizó costarricense. Aquí se encontró al papá de nosotros... Mi mamá se vino para las costas del mar..." (Vargas, 2007:3). Lo anterior ilustra la ruta costera seguida por un grupo de chiricanos. Marciala, conocida como Marciana (Fig. 5), es la quinta hija de Doña Eladias Gómez Zapata, que pudo haber migrado alrededor de la década de 1920. 
Figura 5. Marciala Gómez Zapata

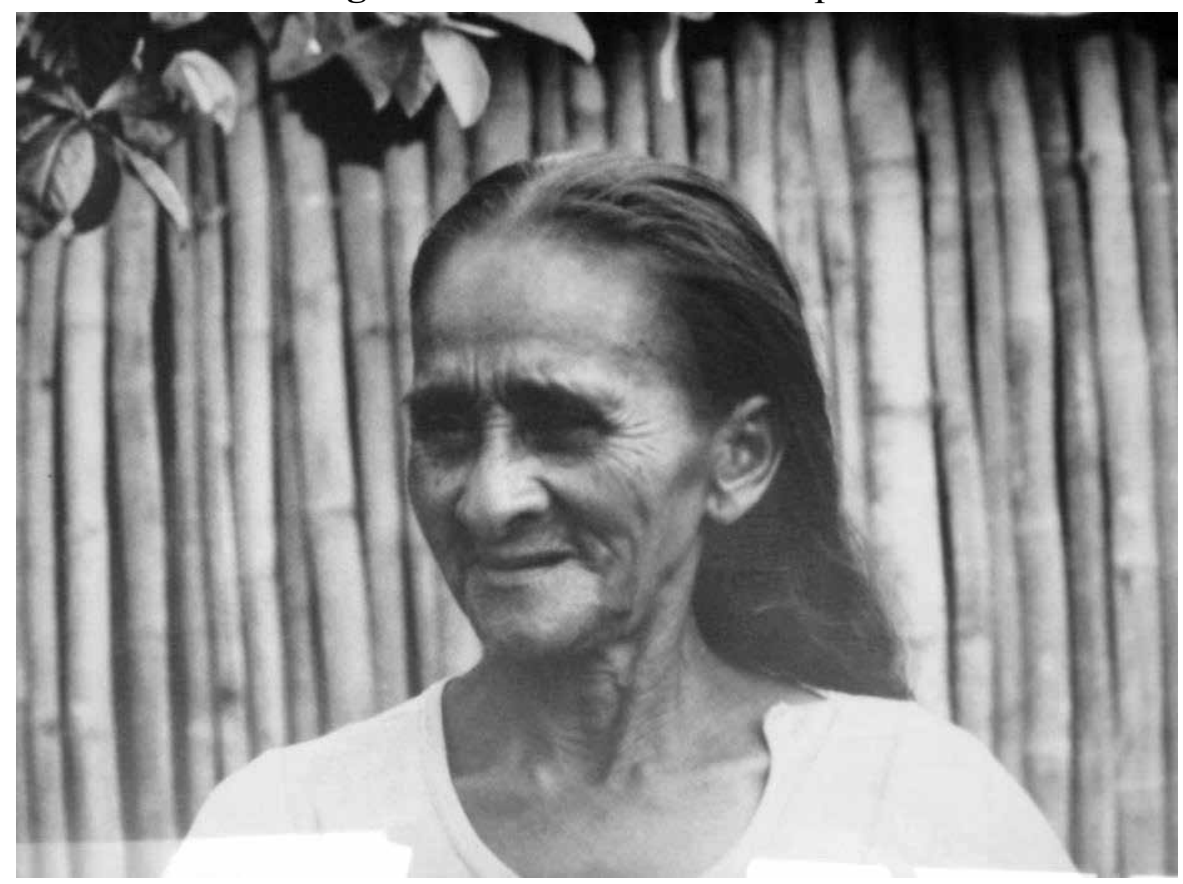

Fotógrafo: Jaime González, 1990

Fuente: ACOSA, Oficina Palmar.

Como se mencionó anteriormente, un significativo grupo de migrantes rápidamente se mezclan con los locales, fundando nuevas familias, debido a que tanto los indígenas como los pobladores del área de interés centran sus actividades económicas en la subsistencia, sin grandes diferencias de clases, generando una identidad más hibrida. Durante este periodo el concepto de nacionalidad no se concebía como en la actualidad, de tal forma que los pobladores no se reconocían como chiricanos, colombianos, costarricenses.

Además de este grupo que se quedó, otros solo ocuparon de forma temporal y posteriormente regresaron a Chiriquí. Aunque no se tienen datos, se puede interpretar que eran los que buscaron refugio por las guerras que acontecían en Panamá y que tenían mejores condiciones económicas en Chiriquí. Un caso de lo anterior es Bernabé Grajales, de padres españoles, quien se estableció en Boca del Río Naranjo en 1902, procurando amparo durante la guerra de Mil Días y se casó con Adelina Morales, una indígena de Térraba 
con quien procreó 13 hijos, que pasada la guerra de los Mil Días regresaron a Chiriquí, aunque siguieron teniendo lazos con la Zona Sur y algunos de sus hijos posteriormente migraron a Potrero Grande (Amador, 2008).

Figura 6. Bernabé Grajales y Adelina Morales aproximadamente en 1950

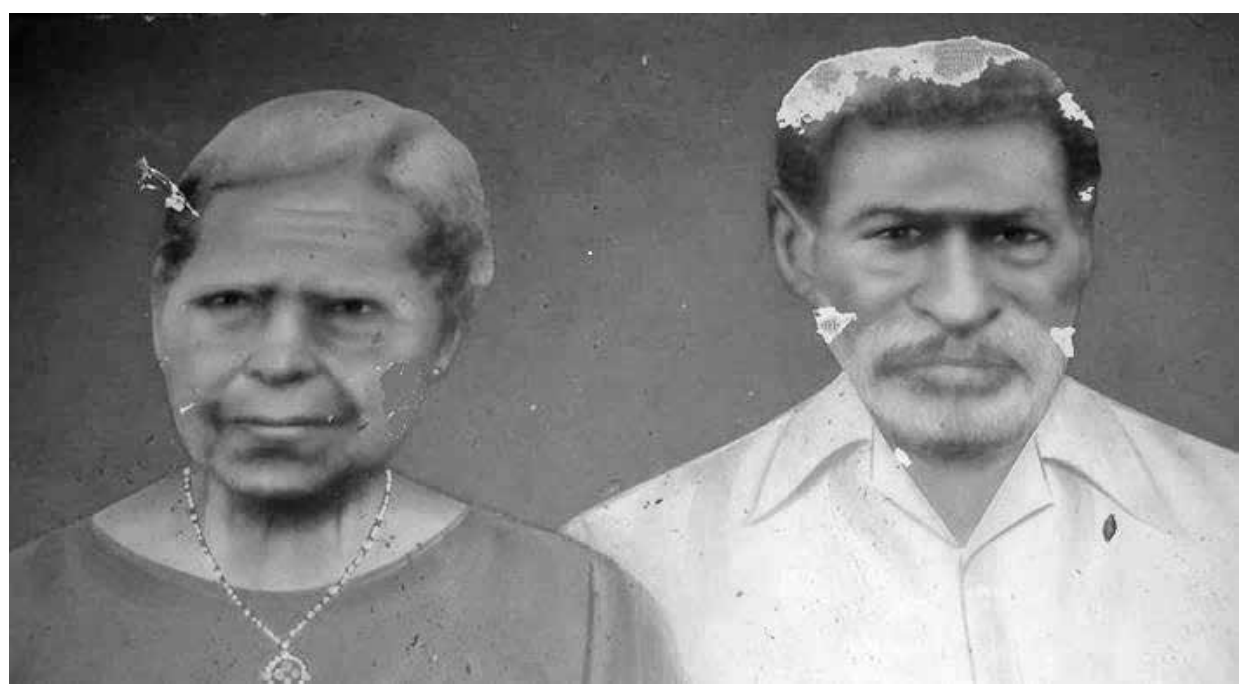

Fotógrafo: Desconocido. Aproximadamente 1950

De acuerdo a Lewis (1983), la búsqueda de nuevas tierras de cultivo debido al agotamiento de estas en la provincia de Chiriquí, así como la estructura agraria dominada por grandes fincas ganaderas fueron los detonantes de este flujo migratorio. Sin embargo, otro elemento que aunó este movimiento fueron las constantes guerras que se realizaban en Colombia como la Guerra de los Mil Días que fue un enfrentamiento civil en Colombia durante octubre del 1899 y noviembre de 1902, en un principio entre el Partido Liberal y el gobierno partidario del Partido Nacional, que generó la intervención de los Estados Unidos con acciones bélicas en Panamá, con el fin, según sus argumentos, de garantizar la seguridad del istmo (Cuestas, 1999). Para la población chiricana, el espacio de refugio más práctico ante esta guerra, de la cual se sentían ajenos fue el Sur de Costa Rica (Barrantes, 2014), donde ya se asentaban algunos chiricanos. Lo anterior coincide con lo expresado por Maximiliano Morales; "Muchos pasaron para allá 
y se volvieron para atrás, (a Chiriqui) otros se quedaron. Es porque esta Revolución de Panamá, empezó por ahí de 1899 y terminó en 1903. Mi papá me contaba, después yo leí algo..." (Amador, 2008:18). Dentro de los pobladores de estas comunidades destacan los siguientes apellidos de origen chiricano: Franchesi, Rodríguez, Zavala, Quintero, Lezcano, Barraza, Gómez, Cedeño, Araúz, Palacios, Serrú, Reyes y Bellanera.

\section{b. Ruta de ocupación terrestre}

Un elemento clave para comprender la migración de los chiricanos al Pacífico Sur de Costa Rica es la ganadería, la cual era la principal actividad productiva de Chiriquí, y en los valles del Río General y del Río Coto abundaban sabanas dominadas por gramíneas, que ya habían sido explotadas por cofradías cartaginesas durante el siglo XVIII, las cuales fueron abandonadas en el siglo XIX. Así, un segundo grupo de chiricanos llegaron a estas tierras procurando estos pastos naturales que dominan en el valle del General, los cuales también existían en la provincia de Chiriquí como menciona Herrera (2006), refiriéndose a la sabana agro-ganadera. A diferencia de la ocupación costera, estos grupos si establecieron poblados y siguiendo el antiguo Camino Real o Camino de las Mulas ingresaron al país por el poblado de Cañas Gordas hasta llegar a Boruca, donde se introdujeron por los valles procurando áreas de pastoreo.

Evidencias de lo anterior, son los nombres de algunos pueblos establecidos por estos como son el Potrero Grande y el mismo Hato Viejo (Actualmente Buenos Aires). Destaca dentro de esta ruta de ocupación la fundación del pueblo de Volcán, el cuál posiblemente tiene este nombre por ser establecido por pobladores del Corregimiento de Volcán del distrito de Bugaba, siendo el pueblo más al norte fundado por los chiricanos en Costa Rica. En estas áreas convivieron migrantes de Chiriquí como del interior de Costa Rica en pueblos sin generar conflictos, debido a que aunque los chiricanos eran en principio más mestizos, los costarricenses también tenía su nivel de mezcla, y así fueron surgiendo familias hibridas como el matrimonio de Manuel Beita Espinoza, quien llegó procedente de Chiriquí con cuatro hermanos en 1887, con Esther Granados, quien fue hija de las primeras familias procedentes de Santa María de Dota (Melquiades Granados Monge y Adela Urena Chinchilla Granados (Barrantes, 2015), quienes se casaron en El General en 1903 y se establecieron en Buenos Aires (Figura 7). 
Figura 7. Manuel Beita Espinoza y Esther Granados Ureña, aproximadamente en 1950.

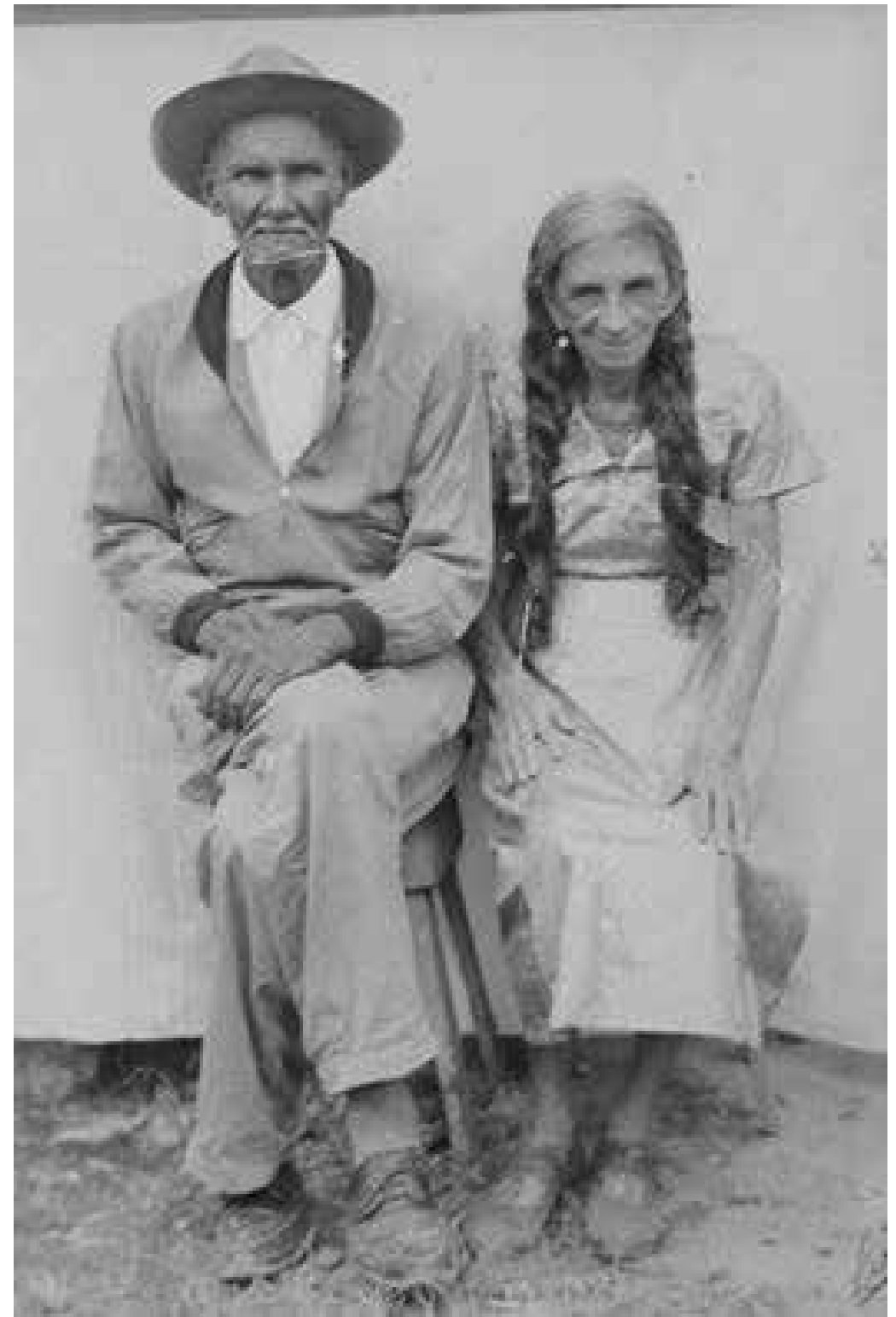

Fotografía: María Elena Álvarez B. Aproximadamente 1950 
Lo anterior se evidencia en la visita del obispo Thiel al actual Buenos Aires cuando afirma "viven allí 25 familias venidas del interior de la República y de Chiriquí" (Chacón, 1986). De acuerdo a Amador (2008), basado en publicaciones de Bozzoli y Wing Ching, (1979) y de Chacón, (1986) los chiricanos se integraron sin dificultad con la población indígena, con excepción de las familias chiricanas de vocación más ganaderas. Sin embargo, esta alianza con los campesinos del interior del país también generó conflictos con los grupos indígenas como lo plantea Rojas (2006) cuando menciona que el poseedor de una tierra con antiguas sepulturas ancestrales era el panameño Claudino Grajales que se asoció a extractores para explotar estos sitios que no contaban con la protección legal de la actualidad. No existen muchas evidencias escritas, pero si abundantes en la tradición oral, sobre la existencia de sepulturas prehispánicas que fueron el sueño dorado de muchos migrantes, especialmente chiricanos. A pesar de lo anterior, algunos chiricanos se emparejaron con mujeres indígenas, especialmente Térrabas, incrementando el mestizaje que actualmente domina en la región, con apellidos que se pueden identificar fácilmente dentro de esta comunidad tales como: Guerra, Atencio, Cedeño, Grajales, Morales, Villarreal, Pitti, Beita, Pinzón, Valdéz, Saldaña, Altamirano y Serracín.

La ocupación de los chiricanos del área de estudio, quizá por ser un proceso espontaneo y poco organizado, no generó conflictos con el gobierno de Costa Rica con excepción del incidente del Rio Coto en 1921, y al contrario se mezcló con los grupos que habitaban el área como los pueblos indígenas y los costarricenses que, igual que ellos eran recién llegados, conformando una alianza para la colonización agrícola y la sobrevivencia. Un indicador de esta fusión, es que, en la primera mitad del siglo XX, la mayoría de intercambio económico se realizaba por medio del Río Térraba. Los productos de Volcán, Buenos Aireas y Potrero Grande, los trasladaban a caballos hasta las riberas de Río Térraba y de ahí en botes hasta El Pozo (actual Puerto Cortés), donde luego se trasladaban posteriormente en lancha hasta Puntarenas (Figura 8). Igual sucedía con la mercadería que se comercializaba en los negocios de Volcán, Buenos Aires y Potrero como la contaba el Médico Jorge A Ramírez Beirute, hijo del primer supervisor escolar en la región y de los propietarios del primer negocio de abarrotes en Volcán. 
Figura 8. Navegación en el río Térraba en 1923

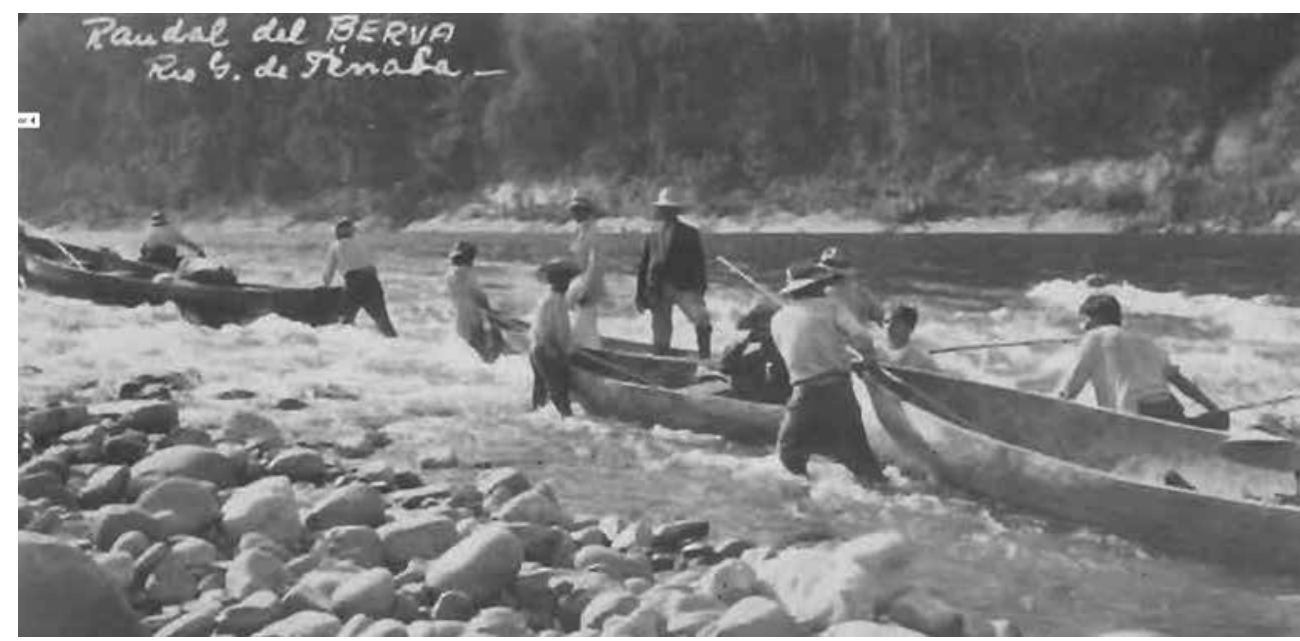

Fotografo Armando Cespedez, Biblioteca Nacional. 1923

Las dificultades de conectividad generaron una estructura de propiedades pequeñas y medianas superficies, basada fundamentalmente en la subsistencia, lo cual varió significativamente de la estructura latifundista que dominaba en Chiriquí. En las dinámicas de organización social se identifican algunas tradiciones de origen indígena como el trabajo colectivo (juntas) en las prácticas de los migrantes chiricanos que denominaban "peonadas". Así, comienza a construirse la identidad de Pacífico Sur, hasta que la localización de la compañía bananera ubicó esta tierra olvidada en el interés del capital transnacional.

\section{Los chiricanos durante enclave bananero en la Zona Sur}

En 1922, la United Fruit Company, preocupada por los efectos adversos de las enfermedades en sus plantaciones de la vertiente Caribe, comienza a explorar territorios en el Pacífico Sur de Costa Rica, ocupando las tierras del río Naranjo, Sierpe y Grande de Térraba. En la Zona Sur, la compañía bananera fue un actor clave en el proceso de la construcción de identidades de esta población, como sucedió en el Litoral Caribe (Fernández, 1970). Este interés de la transnacional irrumpió con el proceso de ocupación de tierras, que en la mayoría de los casos no contaba con documentos legales de propiedad provocando la expulsión o la "compra de 
mejoras", por lo cual la presencia de chiricanos fue rápidamente excluida de las tierras que eran de interés de la Bananera, transformando muchos en obreros, especialmente los ubicados en espacios cerca o dentro de las nuevas plantaciones.

Asimismo, durante 1927, se firma el contrato para establecer en Panamá la subsidiaria, de esta empresa: la Chiriquí Land, en el área limítrofe de la frontera con Costa Rica (Cerdas, 1993). Este proceso inicia un trasiego de fuerza de trabajo en la zona transfronteriza, provocando una ocupación más reciente de chiricanos al lado costarricense y viceversa, donde los negocios de la transnacional superaban los obstáculos limítrofes nacionales, así la fruta que era exportada en el ramal de Puerto González lo hacía primeramente por el Puerto Armuelles en la Panamá. Asimismo, la migración de trabajadores de otros lugares como Guanacaste y Nicaragua, entre otros, fue un aporte para disolver la impronta de la cultura chiricana.

\section{Comentarios finales}

Aún falta mucho por discernir acerca de la construcción de Costa Rica como una nación multiétnica y multicultural, pues únicamente en la medida que se aprecie, como corresponde, los aportes de todos los grupos étnicos que han construido esta nación, es que se superara el estereotipo de la "Suiza Centroamericana", con los efectos xenófobos que esto implica. A partir de notas perdidas en documentos, imágenes y tradición oral, este artículo analiza la presencia de los chiricanos en el Pacífico Sur, sin embargo, aún falta por reconocer de forma precisa, los aportes, especialmente examinando cómo se construye una identidad diferenciada que permita hacer de esta región y de este país un crisol de culturas, donde el espacio presenta una huella de los diversos grupos sociales que cohabitan. Todavía se puede encontrar, alrededor de las rutas marítima-costera o terrestres, algunos vestigios de aquellos chiricanos, que para encontrar refugio o para fundar sus moradas siguiendo, huyendo de guerras o búsqueda de áreas de pastoreo, llegaron a lo que se conoce en la actualidad como el Pacífico Sur, que, en la época colonial, una frontera nacional fragmento una unidad cultural, pero que en fondo continúo siendo una misma región como lo evidencian algunas de sus tradiciones.

Además, como se abordó anteriormente el concepto de nacionalidad, en este tiempo, no responde a pueblos transfronterizos y se asume 
como un concepto estático. Así que, indiscutiblemente en los cimientos de la formación de la identidad del Pacífico Sur, o lo que actualmente se conoce como Zona Sur, están los aportes de los chiricanos como pueblo mestizo que contribuyo a su actual identidad. Se reconoce en algunos de los alimentos tradicionales de Boruca como tamales de arroz, la costumbre de la saloma presente en las borucas y que aún se mantiene entre algunos pobladores de la región, están ligados a la cultura panameña, pero tiene una raíz indígena. Los "ngobe" que son el grupo étnico con mayor afinidad genética con los borucas guardan en su idioma un término especial para la saloma: "nogonengo", lo cual es una evidencia de su raíz indígena. Además de esta huella, existen aportes en cultivos como son los frijoles gandul (Cajanus cajan y papa chiricana (Dioscorea trifida), entre otros. La línea entre lo chiricano y lo campesino costarricense es muy efímera, porque los dos son resultados de aportes de culturas originarias, afro-descendientes e ibéricas, que se entremezclan formando una identidad hibrida.

Emergen diversas interrogantes a resolver en futuras investigaciones, como el nivel de vinculo establecido por los chiricanos con los grupos locales como borucas, terrabas, bribris, cabecares y ngäbe bugle, así como con los migrantes nicaragüenses y guanacastecos que arribaron a la región, sus prácticas agrícolas y culturales, su relación con la sustentabilidad, la huella de los afrodescendientes en esta cultura, entre otros. Aún se requiere revisar muchos documentos extraviados, así como identificar en la tradición oral para testificar la huella de la cultura chiricana en el Sur del País y poder colocarla en el lugar que corresponde como una de las culturas bases de la identidad actual del Pacífico Sur de Costa Rica.

\section{Referencias}

Amador, J.L. (2008). Historia y tradición en Potrero Grande: Un pueblo costarricense de origen chiricano-panameño. San José, Costa Rica: EUNED.

Amador, V. (1978). El camino de mulas en Costa Rica y Panamá. Revista Geográfica de América Central, 7-8(1), 75-84.

Barrantes, C. (2015). Lejano Diquís. San José, Costa Rica: EUNED. Barrantes, C. (2014). Crónicas del Golfo Dulce. San José, Costa Rica: EUNED. 
Barrantes, R. (1998). Origen y relaciones entre los amerindios chibchas de Costa Rica: una perspectiva genética y evolutiva. Memoria del Primer Congreso Científico sobre Pueblos Indígenas de Costa Rica y sus fronteras. Comp.: Bozzoli.

Brenes, G. (1999) Estimación del volumen y características sociodemográficas de los inmigrantes nicaragüenses en Costa Rica. (Tesis del Programa de Estudios de Posgrado en Estadística, Universidad de Costa Rica). San José, Costa Rica.

Cerdas, A. L. (1993). El surgimiento del enclave bananero en el Pacífico Sur. Revista de Historia Núm. 28. Heredia, Costa Rica. Universidad Nacional.

Chacón, L. (1986). Buenos Aires cantón de Puntarenas apuntes para su historia. Revista del Archivo Nacional, 44, 33-50.

Cortés, C. (2010). La invención de un país imaginario. Identidad, invención y mito: Ensayos escogidos. San José, Costa Rica: Editorial Costa Rica.

Cuestas, C. (1999) Panamá y Costa Rica: entre la diplomacia y la guerra. Panamá, Panamá: Editorial Chen.

De Salazar, C. (1993). Un Robinson Tico. San José, Costa Rica: Editorial Fernández-Arce.

Dirección General de Estadísticas y Censo. (1883). Censos de 1883. San José, Costa Rica.

Dirección General de Estadísticas y Censo. (1893). Censos de 1892. San José, Costa Rica.

Dirección General de Estadísticas y Censo. (1927). Censos de 1927. San José, Costa Rica.

Duany, J. (2010). Las diásporas de las Antillas hispánicas: una comparación transnacional. Revista del CESLA, 1(13), 265-286.

Fernández, R. (1970). Las identidades de la población de origen jamaiquino en el Caribe costarricense, 1872-1950. Memoria digital de IX Congreso Centroamericano de Historia. San José, Costa Rica: Universidad de Costa Rica.

Fernández, R. (2005). Cartilla histórica de Costa Rica. San José, Costa Rica: EUNED.

Fernández, L. (1976). Indios, reducciones y el cacao. Editorial Costa Rica. San José, Costa Rica. 
Flores, E. (1983). Geografía de Costa Rica. San José, Costa Rica: EUNED García, M. (1988). Apuntes geohistoricos de la colonización agrícola en la Península de Osa, Costa Rica. Revista Geoistmo, 1(2),27-40. San José. Costa Rica.

Head, L. (2000). Cultural landscapes and environmental change. London: Arnold.

Herrera, G. C. (2006). El Istmo en el mundo. Elementos para una historia ambiental de Panamá. Signos Históricos, 8(16).

Lewis, B. (1983). Reseña histórica de la población y los recursos naturales de la península de Osa, Pacífico Sur. 1948-1981. Revista Geográfica de América Central, 17-18, 123.130. UNA.

Meléndez, C. (2010). Conquistadores y pobladores: Orígenes históricosociales de los costarricenses. San José, Costa Rica: EUNED.

Molina, I. (2002). Costarricense por dicha: Identidad nacional y cambio cultural en Costa Rica durante los siglos XIX y XX. San José, Costa Rica: Editorial Universidad de Costa Rica

Monge, C. (1943). Geografía Social y Humana de Costa Rica. San José, Costa Rica: Imprenta Universal.

Morales, A., Lobo, D. y Jiménez, J. (2014). La travesía laboral de la población Ngäbe Buglé de Costa Rica y Panamá: Características y desafios. San José, Costa Rica: FLACSO.

Nogué, J. (2008). Paisatge i salut. Cataluña, España: Observatori del paisatge de Catalunya

Osorio, A., Salazar, G. y Díaz, A. (1974). Historia de la ciudad de David. Impresora Panamá S.A. Edición Municipal, Panamá

Reinoso, Jose-Hernando [1870-1900] Mapa de América Central. Litografía J.M. Mateu. Librería de Hernando, Madrid, http://catalogo.bne. es/uhtbin/cgisirsi/0/x/0/05? searchdata1=bica0000041154

Rojas, J.R. (2006). Así era Curré: Una visión de la comunidad indígena de Curré de principios del siglo XX hasta la década de los 50. San José, Costa Rica: EUNED

Saborío A. (1941). Costa Rica y Panamá. Revista del Archivo Nacional de Costa Rica 5. San José, Costa Rica.

Sandner, G. (1964). La costa atlántica de Nicaragua, Costa Rica y Panamá. Su conquista y colonización desde principios de la época colonial. 
Serie Geográfica 1. 83-137. San José, Costa Rica: Instituto Geográfico de Costa Rica,

Sauer, C. (2004). Introducción a la geografía histórica. Polis. Revista Latinoamericana, (8).

Sassone, S. M. (2009). Breve geografía histórica de la migración boliviana en la Argentina. Temas de Patrimonio Cultural.

Sibaja, L. F. (1968). El límite sureste de Costa Rica: Reseña histórica desde el laudo Loubet hasta su fijación definitiva. (Tesis. San José, Costa Rica: Universidad de Costa Rica).

Solórzano, J.C. (2013). Los indígenas en la frontera de la colonización; Costa Rica 1502-1930. San José, Costa Rica: EUNED,

Mata, M. T. (1996). Gran Chiriqui, modelos precolombinos y cambios a partir de la conquista. Las raices de la memoria: América Latina, ayer y hoy: Quinto Encuentro Debate (p. 203).

Vargas, E. (2007). Doña Marciala Gómez: relatos de una mujer de los manglares del Río Térraba, en Costa Rica. Segundo Informe de Proyecto de Investigación, El universo social del manglar SierpeTérraba en Costa Rica. Mimeografiado. Universidad Nacional, Heredia. Costa Rica.

Vargas, G. (2012). Geografía de Costa Rica. San José, Costa Rica: EUNED.

Entrevista al médico Jorge A. Ramírez Beirute, 20 de diciembre 2015. 